\title{
Heart Rate as a Marker of Cardiovascular Prognosis
}

${ }^{1}$ Gino Seravalle, ${ }^{2}$ Guido Grassi

\begin{abstract}
Although several studies have shown that elevated heart rate $(\mathrm{HR})$ is a powerful, independent, and consistent predictor of cardiovascular events and all-cause mortality, it is still considered an epiphenomenon of a general disorder rather than an independent risk factor. Several questions regarding the clinical significance of a resting HR as marker of cardiovascular risk are still unanswered, rendering the inclusion of this hemodynamic variable in the list of cardiovascular risk factors problematic, at least for time being. This paper will examine which HR value better reflects the cardiovascular risk, the predictive power, the complex pathophysiological mechanisms underlying the relationship between $\mathrm{HR}$ and cardiovascular risk. It will evaluate whether HR should be considered a true risk factor for cardiovascular diseases or simply a marker of autonomic imbalance, and finally, it will consider the effects of $\mathrm{HR}$ reduction on cardiovascular morbidity.
\end{abstract}

Keywords: Cardiovascular risk, Heart rate, Predictivity, Sympathetic nervous system.

How to cite this article: Seravalle G, Grassi G. Heart Rate as a Marker of Cardiovascular Prognosis. Hypertens J 2016;2(4):189-193.

Source of support: Nil

Conflict of interest: None

\section{INTRODUCTION}

The first study reporting an association between elevated heart rate (HR) values and cardiovascular disease dates back to more than 60 years, with the evidence that subjects with a resting tachycardia state were more prone to developing hypertension. ${ }^{1}$ Since more than 40 epidemiological studies, including the Framingham study, have provided evidence that HR is independently associated with cardiovascular and all-cause mortality, ${ }^{2-5}$ the association between HR and cardiovascular events takes place in patients with and without cardiovascular complications, ${ }^{2,4,6-8}$ which appears to be independent of other risk factors for the atherosclerotic disease and is as consistent as the association between other "classic"

\footnotetext{
1,2Professor

${ }^{1}$ Department of Cardiology, Institute Auxologico Italian, IRCCS San Luca Hospital, Milan, Italy

${ }^{2}$ Department of Clinical and Preventive Medicine, Clinical Medicine, University Milano-Bicocca, Monza, Italy

Corresponding Author: Guido Grassi, Professor, Department of Clinical and Preventive Medicine, Clinical Medicine, University Milano-Bicocca, Monza, Italy, Phone: +390392333357, e-mail: guido.grassi@unimib.it
}

risk factors and cardiovascular disease (Graph 1). Despite this evidence, a number of unaddressed questions (see Table 1) prevent inclusion of HR in the assessment of total cardiovascular risk.

This paper will provide information on the HR as a marker of cardiovascular prognosis in the light of two published Consensus Documents of the European Society of Hypertension., ${ }^{9,10}$

\section{DEFINITION OF HIGH-RESTING HEART RATE}

Tachycardia is currently defined as a HR more than 100 bpm. ${ }^{11}$ Although there is no objective threshold for defining tachycardia from an epidemiological standpoint, the data from most epidemiological and observational studies permit some extrapolation. ${ }^{12}$ Most of these studies found a significant increase in risk starting from a HR well below $100 \mathrm{bpm}$. An attempt to redefine the normal limits of resting HR was made by adding two standard

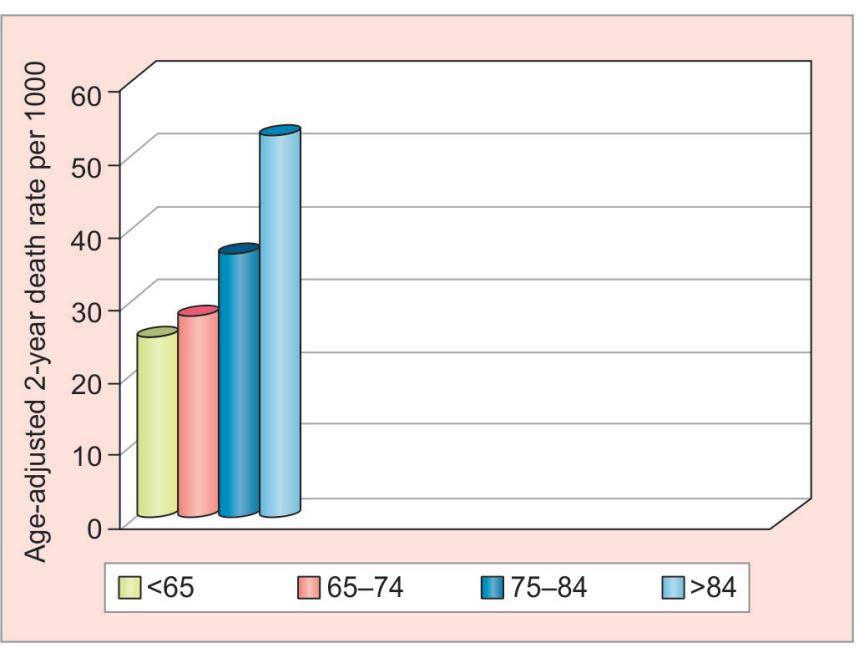

Graph 1: All-cause mortality based on resting heart rate in men with hypertension (data from the Framingham study. Modified from Ref. ${ }^{4}$ )

Table 1: Unanswered questions

- Are data on prognostic importance of heart rate consistent?

- Does evidence pertain only to hypertensive or to general population?

- Is it really an independent risk factor?

- Are all cardiovascular event types involved?

- Do data hold for both genders/all ages/all ethnic groups/all comorbidities, etc.?

- Can the contribution of heart rate to risk be quantified? Is it linear?

- How should heart rate be measured?

- Is there evidence of benefit independently related to heart rate reduction? 
deviations to the mean HR value of a given population. ${ }^{13}$ However, this method showed several limitations. Other studies found an increased risk starting from 80 to $85 \mathrm{bpm}$, which usually corresponded to the lower limit of the top HR quintile. The appropriateness of this choice is supported by the results obtained in hypertensives and in general population with mixture analysis. ${ }^{14}$ Mixture analysis represent an objective method for identifying, within a given population, a subgroup of subjects showing an abnormal distribution of the measure under study, thus permitting qualitative inference. ${ }^{15}$

\section{HOW TO MEASURE HEART RATE}

In most epidemiologic and observational studies, HR was measured in the office by an observer with pulse palpation, electrocardiography, or an automatic device. However, early studies have demonstrated that HR measured in the office is subject to high variability and may be falsely elevated because of the alarm reaction to the doctor's visit, which may be as high as $45 \mathrm{bpm} .^{16}$ Ambulatory HR represents the average of many readings measured out of the office and is devoid of the white coat effect. In addition, ambulatory HR is more reproducible than office HR and has a stronger association with outcome. This issue has been observed in a large study of general population in which 24-hour HR was able to predict total and noncardiovascular mortality but not cardiovascular mortality or any of the fatal combined with nonfatal events. ${ }^{17}$ Also in the Ohasama study, ambulatory HR predicted noncardiovascular disease mortality, but neither daytime nor nighttime HR predicted cardiovascular disease mortality. ${ }^{18}$

Recently, the association between cardiovascular events and ambulatory HR was investigated in the ABPInternational registry. ${ }^{19}$ During a median follow-up of 5 years it has been observed that nighttime HR predicted fatal and nonfatal cardiovascular events more closely than 24-hour HR, whereas daytime and night/day ratio were not associated with outcome. Conflicting results have been obtained for self-assessment of HR at home. While in the Ohasama study a strong relationship was found between home HR and cardiovascular mortality, with a $17 \%$ increase in the risk of mortality for a $5 \mathrm{bpm}$ increase in $\mathrm{HR}^{20}$ this was not the case in the PAMELA study. $^{21}$

\section{PREDICTIVE POWER OF HEART RATE}

The increased risk of cardiovascular events in subjects with tachycardia can be explained by the tendency of individuals with high HR to develop hypertension, obesity, and diabetes in future years. This prospective association has been described in longitudinal cohort studies. In the Framingham study and other studies, the predictive power of HR for the development of hypertension was similar to that of the degree of obesity. ${ }^{22,23}$ The analysis of the HARVEST study has shown that both baseline and follow-up HRs were potent predictors of hypertension development. The persistent tachycardia during 6-year follow-up, but not transient tachycardia, was able to predict the risk of hypertension. ${ }^{24}$ In a 20 -year follow-up in a general population, it has been shown that a higher HR was able to predispose to obesity and diabetes mellitus. ${ }^{25}$ A $30 \%$ increase in the risk for obesity was observed for each $10 \mathrm{bpm}$ increase in baseline $\mathrm{HR}^{26}$ Higher HR is also associated with an increased rate of target organ abnormalities. High HR has shown a longitudinal association with arterial stiffness, an effect that was particularly pronounced in the hypertensive segment of the population. ${ }^{27}$ Higher HR is also prospectively associated with corresponding changes in pulse wave velocity ${ }^{28}$ and with increase in microalbuminuria ${ }^{29}$ or proteinuria. ${ }^{30}$

\section{PATHOGENETIC EVIDENCES}

Several hypotheses have been advanced for explaining the relationship between an elevated HR and cardiovascular risk. Heritability analyses estimated a heritability of resting HR between 21 and 26\%. ${ }^{31}$ Using a candidate gene approach for looking at the genetic determination of resting $H R$, it has been found that a ser49-to-gly (S49G) polymorphism in the beta-1 adrenergic receptor (ADRB1) is associated with resting $\mathrm{HR}^{32}$ Serine homozygotes subjects had the highest mean resting HR. This finding was supported by demonstration of linkage for resting HR on chromosome $4 \mathrm{q}$, in the same region as for long QT syndrome 4 and within the interval of two candidates: Ankyrin-B and myozenin. ${ }^{31}$

Apart from genetic factors, other causes play a large role in the determination of resting HR. High-resting HR reflects an imbalance in the autonomic nervous system, with increased sympathetic activity and/or reduced vagal activity. ${ }^{33}$ Heart rate is a major determinant of myocardial oxygen consumption and reduction of diastolic coronary perfusion time. Thus, an increase in HR may trigger ischemic events and predispose to fatal arrhythmias and sudden death (Flow Chart 1).

The relations among $\mathrm{HR}$, atherosclerotic plaques, and cardiovascular events can also be explained by several direct mechanisms. Recent studies have shown that a defect in bioavailability of nitric oxide (NO) plays a central role in the pathogenesis of this disorder. Interestingly, NO has been implicated in autonomic regulation of various aspects of cardiovascular system and could be the missing link between metabolic syndrome and highresting HR. ${ }^{34}$ Nitric oxide is considered to modulate the autonomic control of HR. It has been suggested that NO 
Flow Chart 1: Role of elevated resting heart rate in the pathophysiology of coronary artery disease

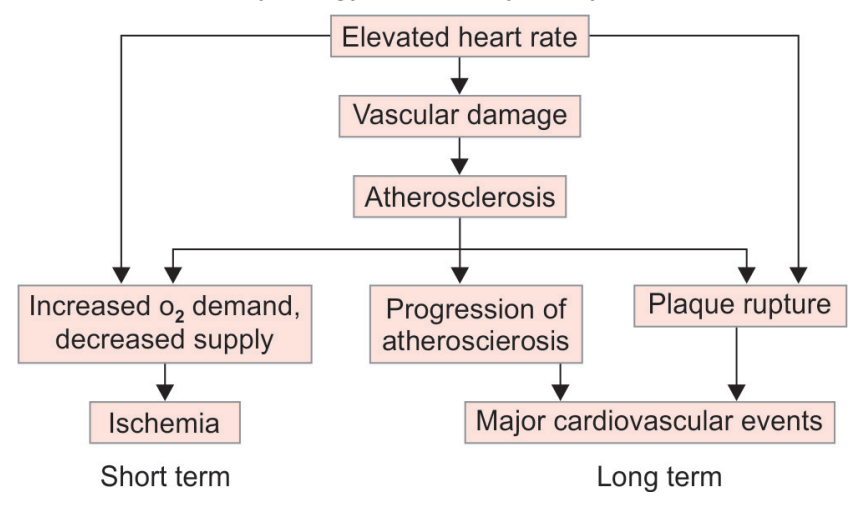

augments cardiac vagal control in healthy subjects as well as in patients with heart failure. ${ }^{35}$ Experimental studies have shown a direct action of high HR or elevated stress index on the development of major atherosclerotic lesions in the coronary arteries, infrarenal aorta, and iliac arteries. ${ }^{36,37}$ Sympathovagal imbalance may be associated with markers of inflammation (fibrinogen, high-sensitivity C-reactive protein, polymorphonuclear leukocytes) and favor the development of atherosclerosis. ${ }^{38}$ High HR reduces the diastolic phase of the cardiac cycle, exposing the endothelium to low and oscillatory end-systolic stress for longer periods, upregulation of proatherogenic genes, and development of the atherosclerotic process. ${ }^{39}$ Reduction in HR has also shown a delay in the progression of coronary atherosclerosis and carotid artery intima thickness. $^{37,40}$

\section{HIGH HEART RATE AS AN INDEPENDENT CARDIOVASCULAR RISK FACTOR}

In several studies, the HR displays a positive relationship with blood pressure values, body weight, triglycerides, insulin, and glucose metabolism, raising the possibility that the ability of this hemodynamic variable to predict cardiovascular events is somewhat unspecific and at least in part dependent on other well-known cardiovascular risk factors. However, in the follow-up of two recent surveys, an association between $\mathrm{HR}$, sudden death and acute coronary events has been reported, and it remained significant even after adjustment for age, body mass index, smoking, blood pressure, lipid profile, diabetes, and history of cardiovascular disease. ${ }^{41,42}$ Interestingly, in these studies the predictive power of HR for fatal cardiovascular and noncardiovascular events was often greater than that of hypertension and/or hypercholesterolemia and manifest not only in ischemic heart disease, but also in heart failure, hypertension, and diabetes. ${ }^{43}$ Multiple follow-up studies confirmed these data. The CORDIS study $^{44}$ found that resting HR was strongly associated with both all-cause [relative risk (RR): 2.23, confidence interval (CI): 1.4-3.6, resting HR > 90 vs < 70 bpm] and cardiovascular mortality after correcting for risk factors. The PPS study ${ }^{45}$ found that mortality could be predicted by resting heart frequency in middle-aged males followed for 17 years. The MATISS project verified that in low-risk Italian population, HR increment was associated with a RR increase of 1.52 for all-cause mortality, 1.63 for cardiovascular mortality, and 1.47 for noncardiovascular mortality. ${ }^{46}$ The risk is graded, i.e., the risk rises with increasing resting HR. ${ }^{5}$ Based on this evidence it has been proposed that life span could be predetermined using allometric scales based on resting $\mathrm{HR}^{47}$

\section{REDUCING HEART RATE: WHICH BENEFITS?}

The energetic theory suggests that total energy per life is predetermined and depends on HR; thus life become shorter when energy is consumed by increasing HR while lowering resting HR should increase the life span. In wildness, hibernation acts in this way. We can say that hibernation is not possible in humans but we have several possibilities to act on HR. Regular physical exercise, through increase in parasympathetic activity and decrease in sympathetic tone, is a well-known intervention to lower resting HR and increase survival. In heart diseases (ischemic, heart failure) reduction in HR is one of the first therapeutic choice. ${ }^{10}$ The reduction in HR allows to minimize the myocardial oxygen demand and improves subendocardial blood flow, reduces the risk of plaque rupture, and reduces sudden death. Other than regular exercise, as part of a more complete change in lifestyle, individuals may obtain benefit by HR-lowering drugs. Beta-blockers reduce both resting HR and the response of the HR to exercise. The reduction of HR is accompanied by a decrease in peripheral blood pressure with consequent reduction in cardiac oxygen consumption and a longer diastolic filling time, allowing for increased coronary perfusion. The benefits in terms of prognosis of reducing HR by drugs are limited to myocardial infarction and heart failure, i.e., two conditions in which administration of beta-blockers have been shown to reduce mortality and positively affect heart failure. ${ }^{48,49}$ In contrast, no study has so far addressed this issue in hypertension and thus no evidence is available on the benefits of the HR reduction in this condition. Thus, despite the lack of conclusive data, HR reduction by antihypertensive agents is suggested to have beneficial effects in hypertension while it is a strong recommendation in the post-myocardial phases and in heart failure patients. ${ }^{10}$

The importance of heart rate (reduction) in patients with congestive heart failure was demonstrated in the SHIFT study. ${ }^{50}$ In this study a heart rate of $>70$ beats/ minute was associated with worsening heart failure and increased mortality. In another randomized clinical trial, 
'BEAUTIFUL' Ivabradine (a drug which lowers the heart rate) showed a favorable trend in outcomes of patients with coronary artery disease and left ventricular dysfunction. ${ }^{51}$ Taken together, these studies indicate that a reduction in heart rate is of prognostic importance in patients with congestive heart failure.

\section{REFERENCES}

1. Levy RL, White PD, Stroud WD, Hillman CC. Transient tachycardia: prognostic significance alone and in association with transient hypertension. JAMA 1945;129(9):585-588.

2. Kannel WB, Kannel C, Paffenbarger RS Jr, Cupples LA. Heart rate and cardiovascular mortality: the Framingham study. Am Heart J 1987 Jun;113(6):1489-1494.

3. Dyer AR, Persky V, Stamler J, Paul O, Shekelle RB, Berkson DM, Lepper M, Schoenberger JA, Lindberg HA. Heart rate as a prognostic factor for coronary heart disease and mortality: findings in three Chicago epidemiologic studies. Am J Epidemiol 1980 Dec;112(6):736-749.

4. Gillman MW, Kannel WB, Belanger A, D'Agostino RB. Influence of heart rate on mortality among persons with hypertension: the Framingham study. Am Heart J 1993 Apr;125(4):1148-1154.

5. Gillum RF, Makuc DM, Feldman JJ. Pulse rate, coronary heart disease, and death: the NHANES I Epidemiologic follow-up study. Am Heart J 1991 Jan;121(1 Pt 1):172-177.

6. Palatini P, Thijs L, Staessen JA, Fagard RH, Bulpitt CJ, Clement DL, de Leeuw PW, Jaaskivi M, Leonetti G, Nachev $C$, et al. Predictive value of clinic and ambulatory heart rate for mortality in elderly subjects with systolic hypertension. Arch Intern Med 2002 Nov 11;162(20):2313-2321.

7. Diaz A, Bourassa MG, Guertin MC, Tardif JC. Long term prognostic values of resting heart rate in patients with suspected or proven coronary artery disease. Eur Heart J 2005 May;26(10):967-974.

8. Chang M, Havlik RJ, Corti MC, Chaves PH, Fried LP, Guralnik JM. Relation of heart rate at rest and mortality in the Women's Health and Aging Study. Am J Cardiol 2003 Dec 1;92(11):1294-1299.

9. Palatini P, Benetos A, Grassi G, Julius S, Kjeldsen SE, Mancia G, Narkiewicz K, Parati G, Pessina AC, Ruilope LM, et al. Identification and management of the hypertensive patient with elevated heart rate: statement of a European Society of Hypertension Consensus Meeting. J Hypertens 2006 Apr;24(4):603-610.

10. Palatini P, Rosei EA, Casiglia E, Chalmers J, Ferrari R, Grassi G, Inoue $\mathrm{T}$, Jelakovic $\mathrm{B}$, Jensen MT, Julius $\mathrm{S}$, et al. Management of the hypertensive patient with elevated heart rate: statement of the second consensus conference endorsed by the European Society of Hypertension. J Hypertens 2016 May; 34(5):813-821.

11. Longo LD, Fauci AS, Kasper ED, Hauser SL, Jameson JL, Loscalzo J. Harrison's principles of internal medicine. 18th ed. New York (NY): McGraw-Hill; 2012.

12. Palatini P. Need for a revision of the normal limits of resting heart rate. Hypertension 1999 Feb;33(2):622-625.

13. Spodick DH. Redefinition of normal sinus heart rate. Chest 1993 Sep;104(3):939-941.

14. Palatini P, Casiglia E, Pauletto P, Staessen J, Kaciroti N, Julius S. Relationship of tachycardia with high blood pressure and metabolic abnormalities. A study with mixture analysis in three populations. Hypertension 1997 Nov;30(5):1267-1273.

15. Shork NJ, Weder AB, Schork MA, Bassett DR, Julius S. Disease entities, mixed multinormal distributions, and the role of the hyperkinetic state in the pathogenesis of hypertension. Stat Med 1990 Mar;9(3):301-314.

16. Mancia G, Parati G, Pomidossi G, Grassi G, Casadei R, Zanchetti A. Alerting reaction and rise in blood pressure during measurement by physician and nurse. Hypertension 1987 Feb;9(2):209-215.

17. Hansen TW, Thijs L, Boggia J, Li Y, Kikuya M, Björklund-Bodegård K, Richart T, Ohkubo T, Jeppesen J, Torp-Pedersen C, et al. Prognostic value of ambulatory heart rate revisited in 6928 subjects from 6 populations. Hypertension 2008 Aug;52(2):229-235.

18. Hozawa A,InoueR, OhkuboT, Kikuya M, MetokiH, Asayama K, Hara A, Hirose T, Kanno A, Obara T, et al. Predictive value of ambulatory heart rate in the Japanese general population: the Ohasama study. J Hypertens 2008 Aug;26(8):1571-1576.

19. Palatini P, Reboldi G, Beilin LJ, Eguchi K, Imai Y, Kario K, Ohkubo T, Pierdomenico SD, Saladini F, Schwartz JE, et al. Predictive value of night-time heart rate for cardiovascular events in hypertension. The ABP-International study. Int J Cardiol 2013 Sep 30;168(2):1490-1495.

20. Hozawa A, Ohkubo T, Kikuya M, Ugajin T, Yamaguchi J, Asayama K, Metoki H, Ohmori K, Hoshi H, Hashimoto J, et al. Prognostic value of home heart rate for cardiovascular mortality in the general population: the Ohasama study. Am J Hyeprtens 2004 Nov;17(11 Pt 1):1005-1010.

21. Sega R, Facchetti R, Bombelli M, Cesana G, Corrao G, Grassi G, Mancia G. Prognostic value of ambulatory and home blood pressure compared with office blood pressure in the general population: follow-up results from the Pressioni Arteriose Monitorate E Loro Associazioni (PAMELA) study. Circulation 2005 Apr 12;111(14):1777-1783.

22. Kannel WB, Brand N, Skinner JJ Jr, Dawber TR, McNamara PM. The relation of adiposity to blood pressure and development of hypertension. Ann Intern Med 1967 Jul;67(1):48-59.

23. Reed D, McGee D, Yano K. Biological and social correlates of blood pressure among Japanese men in Hawaii. Hypertension 1982 May-Jun;4(3):406-414.

24. Palatini P, Dorigatti F, Zaetta V, Mormino P, Mazzer A, Bortolazzi A, D’Este D, Pegoraro F, Milani L, Mos L, et al. Heart rate as a predictor of development of sustained hypertension in subjects screened for stage I hypertension: the HARVEST study. J Hypertens 2006 Sep;24(9):1873-1880.

25. Shigetoh Y, Adachi H, Yamagishi S, Enomoto M, Fukami A, Otsuka M, Kumagae S, Furuki K, Nanjo Y, Imaizumi T. Higher heart rate may predispose to obesity and diabetes mellitus: 20-years prospective study in a general population. Am J Hypertens 2009 Feb;22(2):151-155.

26. Palatini $\mathrm{P}$, Mos L, Santonastaso M, Zanatta N, Mormino P, Saladini F, Bortolazzi A, Cozzio S, Garavelli G, HARVEST Study Group. Resting heart rate as a predictor of body weight gain in the early stage of hypertension. Obesity 2011 Mar;19(3): 618-623.

27. Benetos A, Adamopoulos C, Bureau JM, Temmar M, Labat C, Bean K, Thomas F, Pannier B, Asmar R, Zureik M, et al. Determinants of accelerated progression of arterial stiffness in normotensive and treated hypertensive subjects over a 6-year period. Circulation 2002 Mar 12;105(10):1202-1207. 
28. Tomiyama H,Hashimoto H, Tanaka H,Matsumoto C, Odaira M, Yamada J, Yoshida M, Shiina K, Nagata M, Yamashina A. Synergistic relationship between changes in pulse wave velocity and changes in the heart rate in middle-aged Japanese adults: a prospective study. J Hypertens 2010 Apr;28(4): 687-694.

29. Bohm M, Reil JC, Danchin N, Thoenes M, Bramlage P, Volpe M. Association of heart rate with microalbuminuria in cardiovascular risk patients: data from I-SEARCH. J Hypertens 2008 Jan;26(1):18-25.

30. Inoue $T$, Iseki K, Iseki C, Ohya $Y$, Kinjo K, Takishita S. Heart rate as a risk factor for developing chronic kidney disease: longitudinal analysis of a screened cohort. Clin Exp Nephrol 2009 Oct;13(5):487-493.

31. Martin LJ,Comuzzie AG, Sonnenberg GE, MyklebustJ,James R, Marks J, Blangero J, Kissebah AH. Major quantitative trait locus for resting heart rate maps to a region on chromosome 4 . Hypertension 2004 May;43(5):1146-1151.

32. Ranade $K$, Jorgenson E, Sheu WH, Pei D, Hsiung CA, Chiang FT, Chen YD, Pratt R, Olshen RA, Curb D, et al. A polymorphism in the beta 1 adrenergic receptor is associated with resting heart rate. Am J Hum Genet 2002 Apr;70(4): 935-942.

33. Grassi G, Vailati S, Bertinieri G, Seravalle G, Stella ML, Dell'Oro R, Mancia G. Heart rate as marker of sympathetic activity. J Hypertens 1998 Nov;16(11):1635-1639.

34. Sartori C, Lepori M, Scherrer U. Interaction between nitric oxide and the cholinergic and sympathetic nervous system in cardiovascular control in humans. Pharmacol Ther 2005 May;106(2):209-220.

35. Chowdhary S, Valle JC, Fletcher J, Ross HF, Coote JH, Townsend JN. Nitric oxide and cardiac autonomic control in humans. Hypertension 2000 Aug;36(2):264-269.

36. Beere PA, Glagov S, Zarins CK. Retarding effect of lowered heart rate on coronary atherosclerosis. Science 1984 Oct 12;226(4671):180-182.

37. Kaplan JR, Manuck SB, Adams MR, Weingand KW, Clarkson TB. Inhibition of coronary atherosclerosis by propranolol in behaviorally predisposed monkeys fed an atherogenic diet. Circulation 1987 Dec;76(6):1364-1372.

38. Lang CC, Gupta S, Kalra P, Keavney B, Menown I, Morley C, Padmanabhan S. Elevated heart rate and cardiovascular outcomes in patients with coronary artery disease: clinical evidence and pathophysiological mechanisms. Atherosclerosis 2010 Sep;212(1):1-8.

39. Giannoglou GD, Chatzizisis YS, Zamboulis C, Parcharidis GE, Mikhailidis DP, Louridas GE. Elevated heart rate and athero- sclerosis: an overview of the pathogenetic mechanisms. Int J Cardiol 2008 Jun 6;126(3):302-312.

40. Hedlad B, Wikstrand J, Jazon L, Wedel H, Berglund G. Low-dose metoprololCR/XL:fluvastatin slow progression of carotid intima-media thickness: main results from the Beta-blocker Cholesterol-Lowering Asymptomatic Plaque Study (BCAPS). Circulation 2001 Apr 3;103(13):1721-1726.

41. Greenland P, Daviglus ML, Dyer AR, Liu K, Huang CF, Goldberger JJ, Stamler J. Resting heart rate is a risk factor for cardiovascular and noncardiovascular mortality: the Chicago Heart Association Detection Project in Industry. Am J Epidemiol 1999 May 1;149(9):853-862.

42. Jouven $X$, Desnos $M$, Guerot $C$, Ducimetière P. Predicting sudden death in the population: the Paris Prospective Study I. N Engl J Med 2005 May 12;352(19):1951-1958.

43. Palatini P, Julius S. Heart rate and the cardiovascular risk. J Hypertens 1997 Jan;15(1):3-17.

44. Kristal-Boneh E, Silber H, Harari G, Froom P. The association of rating heart rate with cardiovascular, cancer and all-cause mortality. Eight year follow-up of 3527 male Israeli employees (the CORDIS study). Eur Heart J 2000 Jan;21(2):116-124.

45. Filipovský J, Ducimetière P, Safar ME. Prognostic significance of exercise blood pressure and heart rate in middle-aged men. Hypertension 1992 Sep;20(3):333-339.

46. Seccareccia F, Pannozzo F, Dima F, Minoprio A, Menditto A, Lo Noce C, Giampaoli S, Malattie Cardiovascolari Aterosclerotiche Istituto Superiore di Sanita Project. Heart rate as a predictor of mortality: the MATISS projects. Am J Public Health 2001 Aug;91(8):1258-1263.

47. Levine HJ. Rest heart rate and life expectancy. J Am Coll Cardiol 1997 Oct;30(4):1104-1106.

48. Cucherat M. Quantitative relationship between resting heart rate reduction and magnitude of clinical benefits in postmyocardial infarction: a meta-regression of randomized clinical trials. Eur Heart J 2007 Dec;28(24):3012-3019.

49. Kjekshus J, Gullestad L. Heart rate as a therapeutic target in heart failure. Eur Heart J 1999;1(Suppl H):H64-H69.

50. Swedberg K, Komajda M, Böhm M, Borer JS, Ford I, DubostBrama A, Lerebours G, Tavazzi L; SHIFT Investigators. Ivabradine and outcomes in chronic heart failure (SHIFT): a randomised placebo-controlled study. Lancet 2010 Sep 11;376(9744):875-885.

51. Fox K, Ford I, Steg PG, Tendera M, Ferrari R; BEAUTIFUL Investigators. Ivabradine for patients with stable coronary artery disease and left-ventricular systolic dysfunction (BEAUTIFUL): a randomised, double-blind, placebocontrolled trial. Lancet 2008 Sep 6;372(9641):807-816. 